\title{
Postoperative posterior lumbar muscle changes and their relationship to segmental motion preservation or restriction: a randomized prospective study
}

\author{
Patrick Strube, MD, ${ }^{1}$ Michael Putzier, MD, ${ }^{2}$ Florian Streitparth, MD, ${ }^{3}$ Eike K. Hoff, MD, ${ }^{2}$ \\ and Tony Hartwig, MD2
}

${ }^{1}$ Klinik für Orthopädie der Friedrich-Schiller-Universität Jena, Waldkrankenhaus "Rudolf Elle" gGmbH, Eisenberg; ${ }^{2}$ Klinik für Orthopädie, Centrum für Muskuloskeletale Chirurgie, Charité - Universitätsmedizin Berlin; and ${ }^{3}$ Department of Radiology, Charité - Universitätsmedizin Berlin, Germany

OBJECTIVE To date, it remains unclear whether the preservation of segmental motion by total disc replacement (TDR) or motion restriction by stand-alone anterior lumbar interbody fusion (ALIF) have an influence on postoperative degeneration of the posterior paraspinal muscles or the associated clinical results. Therefore, the purpose of the present prospective randomized study was to evaluate the clinical parameters and 3D quantitative radiological changes in the paraspinal muscles of the lumbar spine in surgically treated segments and superior adjacent segments after ALIF and TDR.

METHODS A total of 50 patients with chronic low-back pain caused by single-level intervertebral disc degeneration (Pfirrmann Grade $\geq$ III) and/or osteochondrosis (Modic Type $\leq 2$ ) without symptomatic facet joint degeneration (Fujiwara Grade $\leq 2$, infiltration test) of the segments L4-5 or L5-S1 were randomly assigned to 2 treatment groups. Twenty-five patients were treated with a stand-alone ALIF and the remaining 25 patients underwent TDR. For ALIF and TDR, a retroperitoneal approach was used. At 1 week and at 12 months after surgery, CT was used to analyze paraspinal lumbar muscle tissue volume and relative fat content. Residual muscle tissue volume at 12 months and change in the relative fat content were compared between the groups. In addition, clinical parameters (visual analog scale [VAS] for low-back pain and Oswestry Disability Index [ODI] Questionnaire Version 2 for function) were compared.

RESULTS Compared with 1 week after surgery, the radiological analysis at 12 months revealed a small decrease in the posterior muscle volume (the mean decrease was $<2.5 \%$ ), along with a small increase in the relative fat content (the mean increase was $<1.9 \%$ ), in both groups at the index and superior adjacent segments. At the adjacent segment, the ALIF group presented significantly less muscle tissue volume atrophy and a smaller increase in fat content compared with the TDR group. At final follow-up, the clinical parameters related to pain and function were significantly improved in both groups compared with 1 week postsurgery, but there were no differences between the groups.

CONCLUSIONS Motion restriction via stand-alone ALIF and motion preservation via TDR both present small changes in the posterior lumbar paraspinal muscles with regard to volume atrophy or fatty degeneration at the index and superior adjacent segments. Therefore, although the clinical outcome was not affected by the observed muscular changes, the authors concluded that the expected negative influence of motion restriction on the posterior muscles compared with motion preservation does not occur on a clinically relevant level.

http://thejns.org/doi/abs/10.3171/2015.3.SPINE14997

KEY WORDS muscle atrophy; fatty degeneration; total disc replacement; ALIF; muscle evaluation; lumbar spine

$\mathrm{P}$ ERSISTENT or recurrent lumbar pain is a common problem in patients after spinal surgery. ${ }^{34}$ Although other reasons have been discussed, 2,9 an overload of the paravertebral muscles after surgical intervention has been suggested as the major cause of postoperative pain..$^{20,35}$ Postsurgery short- and long-term progression of lumbar muscle degeneration, consisting of a decrease in the muscle volume and fatty reorganization of the muscle tissue during healing, negatively influences the muscle load capacity..$^{13}$ Furthermore, this lumbar muscle degeneration seems to be strongly correlated to inferior physical and mental outcomes of fusion and to pain..$^{35}$ Because of the multisegmental anatomy of the stabilizing posterior paravertebral muscles, chronic damage might also influ-

ABBREVIATIONS ALIF = anterior lumbar interbody fusion; CSA = cross-sectional area; IQR = interquartile range; ODI = Oswestry Disability Index; RM-ANOVA = analysis of variance for repeated measures; $\mathrm{ROI}=$ region of interest; $\mathrm{ROM}=$ range of motion; TDR = total disc replacement; VAS = visual analog scale.

SUBMITTED September 29, 2014. ACCEPTED March 26, 2015.

INCLUDE WHEN CITING Published online September 11, 2015; DOI: 10.3171/2015.3.SPINE14997 
ence the development or progression of adjacent-segment degeneration, which plays an important role in the clinical success of motion-preserving surgical treatment such as total disc replacement (TDR). ${ }^{18}$

Preoperative fatty degeneration of the posterior paravertebral muscles is known to result in an inferior clinical outcome following TDR. ${ }^{18}$ This leads to the assumption that muscular function is essential for the success of motion-preserving surgical treatment of degenerated segments. Nevertheless, because of the geometrical segment changes caused by the surgical procedure, ${ }^{29,33}$ muscular changes following TDR may also occur over time, but this has not been studied.

Volume atrophy and fatty remodulation of the lower back paravertebral muscles have been studied using CT and MRI. These muscular changes have been described after posterior fusion techniques such as transforaminal lumbar interbody fusion (TLIF) or posterior lumbar interbody fusion (PLIF). The extent of the muscular damage was related to the invasiveness of the surgical approach and correlated clinically, especially to early postoperative results. ${ }^{6,713,24,34}$ However, based on the nature of posterior fusion techniques, the nondirect effect of segmental motion restriction on volume atrophy and fatty remodulation in these studies could not be distinguished from the direct traumatic damage caused by the surgical approach. With regard to the problems of adjacent-segment degeneration, postoperatively persistent or recurrent low-back pain, and availability of stand-alone anterior lumbar interbody fusion (ALIF) devices that completely avoid the approachrelated direct damage to posterior paravertebral muscles, ${ }^{32}$ the ability to distinguish such effects would impact the choice of surgical technique and segmental fusion approach.

Therefore, the purpose of the present study was to compare volume atrophy and fatty degeneration of the posterior paravertebral muscles between single-level stand-alone ALIF and TDR of the segments L4-5 or L5-S1 at the index and superior adjacent segments. The primary hypothesis of our study was that the motion restriction (fusion) procedure causes a loss of muscle volume and increase in muscle fat content, whereas motion preservation (TDR) leads to an increase of muscle volume and decrease in fat content over 1 year. In addition, we expected a superior clinical outcome after TDR compared with ALIF.

\section{Methods \\ Study Design}

Patients who presented with persistent lumbosacral complaints after unsuccessful conservative therapy over a period of at least 6 months were enrolled in this prospective, randomized, nonblinded study. In addition, painful (as shown by provocative discography and discoblock in open $\mathrm{MRI}^{27,30}$ ) single-level degenerative disc disease (Pfirrmann ${ }^{26}$ Grade $\geq$ III and/or Modic ${ }^{22}$ Type $\leq 2$ ) of segments L5-S1 or L4-5 (as observed by MRI) had to be present. Radicular symptoms based on neuroforaminal stenosis caused by degeneration of the index segment did not lead to patient exclusion.

Patients were excluded from the study if they had de- generation of adjacent segments as verified by MRI. Additionally, patients with facet joint degeneration (Fujiwara ${ }^{10}$ Grade $\geq 3$ ) at any segment of the lumbar spine were excluded. A Fujiwara Grade 2 led to diagnostic facet joint infiltration, and patients were excluded from the study in the case of positive infiltration test results. Further exclusion criteria included additional degenerative findings; spinal stenosis with the need for decompression; spinal deformities; spondylolisthesis Meyerding ${ }^{21}$ Grade $\geq$ I or destructive processes; previous operations on the lumbar spine; long-term medication with corticoids or NSAIDs; psychological distress syndrome or a somatization disorder of Grade $\geq$ II according to Gerbershagen; $; 2$ presence of osteoporosis, kidney disease, liver disease, muscle disease, or malignant tumors; a body mass index $>30 \mathrm{~kg} / \mathrm{m}^{2}$; age $>$ 65 years or $<18$ years; pregnancy; allergies to $\mathrm{Co}, \mathrm{Cr}, \mathrm{Ni}$, $\mathrm{Ti}$; and chronic nicotine, alcohol, or drug abuse.

The study was approved by the local Research Ethics Committee (no. EA1/209/09), and informed written consent was obtained from each patient.

\section{Patient Groups}

An a priori power analysis (NCSS 2004-PASS 2005; $\alpha=0.05, \beta=0.20$ ) was performed to calculate the group size. This analysis was based on 50 retrospective image analyses of the primary radiological outcome parameters and application of the described measuring method. Based on the difference in the multifidus muscle volume atrophy between healthy individuals and patients with low-back pain, ${ }^{8}$ the clinically relevant differences were set to $30 \mathrm{~cm}^{3}$ $\left(\mathrm{SD} 35 \mathrm{~cm}^{3}\right.$ ) for muscle volume and $20 \%$ for fat content (SD 8\%), which resulted in a group size of 21 subjects. Accepting a possible dropout rate of approximately $15 \%$, the group size was set to 25 subjects.

A total of 50 patients were included in the study and randomly assigned to 1 of 2 groups of 25 patients each. Randomization was performed using RandList Software (DatInf $\mathrm{GmbH}$ ). Patients in the TDR group underwent a TDR (Maverick A-MAV, Medtronic) at the index segment, whereas patients in the ALIF group underwent a single-level stand-alone ALIF (SYNFIX LR, DePuy Synthes Spine Inc.). Patient demographic data and segmental distribution per group are presented in Table 1.

\section{Surgical Procedure}

All of the surgeries were performed by the same senior surgeon (M.P.) via a pararectal retroperitoneal approach. Prior to implant placement, the intervertebral disc was resected and the cartilaginous endplate was removed. The implant (TDR or stand-alone ALIF cage) dimensions, angulations, and height were defined by fitting a test specimen/template according to the individual size and angle of the intervertebral space. The implant was press-fit anchored after distraction and resection of the posterior longitudinal ligament. In the ALIF group, the polyetheretherketone (PEEK) cage was augmented with allogenic freeze-dried corticocancellous bone grafts from the local bone bank and fixed via 4 angle-stable screws into the adjacent vertebrae. Each patient was mobilized without an orthosis and administered physiotherapy from the first 
TABLE 1. Patient demographic data for 48 patients with chronic low-back pain due to single-level intervertebral disc degeneration

\begin{tabular}{cccc}
\hline Parameter & $\begin{array}{c}\text { TDR Group } \\
(\mathrm{n}=23)\end{array}$ & $\begin{array}{c}\text { ALIF Group } \\
(\mathrm{n}=25)\end{array}$ & $\begin{array}{c}\mathrm{p} \\
\text { Value }\end{array}$ \\
\hline $\begin{array}{c}\text { Mean age at surgery, } \\
\text { yrs (range) }\end{array}$ & $47.3(35-59)$ & $48.4(38-58)$ & 0.601 \\
\hline $\begin{array}{c}\text { Index segment, } \\
\text { L4-5/L5-S1 } \dagger\end{array}$ & $9: 14$ & $10: 15$ & 0.951 \\
\hline Sex, female/male $\dagger$ & $13: 10$ & $15: 10$ & 0.807 \\
\hline Mean BMl, $\mathrm{kg} / \mathrm{m}^{2 *}$ & 25.8 & 26.6 & 0.406 \\
\hline
\end{tabular}

$\mathrm{BMI}=$ body mass index.

* The $p$ values are from a 2-sided Student t-test.

$\dagger$ The $p$ values are from a chi-square test.

postoperative day onward. Physiotherapy was performed twice a week for approximately 9 weeks postoperatively. All physiotherapists were advised to isometrically strengthen trunk and back muscles and to avoid exercises that extend the maximal range of motion (ROM).

\section{Data Collection}

For group comparisons, all of the patients were assessed using a visual analog scale (VAS) (performed preoperatively and at 1 week and at 12 months postoperatively) for back pain. The Oswestry Disability Index (ODI) Questionnaire Version 2 (according to the method of Fairbank) was used to assess function (performed preoperatively and 12 months postoperatively). Preoperatively, 1 week postoperatively, and 12 months postoperatively, radiographs of L3-S1 were acquired with the patient in the upright standing position (anteroposterior and lateral view) to identify implant-associated failures. Additionally, flexion-extension (lateral view) radiographs were taken to monitor the segmental ROM of the index segment at 12 months after surgery. Major and minor complications were also recorded.

Based on a recently published protocol, ${ }^{15}$ which is only briefly presented here, patients received an artifact-reduced CT (multidetector CT [MDCT] 16-Zeilen, Toshiba) of the index and superior adjacent segments for registration of implant-associated complications, such as migration, loosening, or nonunion (according to criteria published elsewhere ${ }^{28}$ ), as well as for 3D measurement of the paravertebral muscles at 1 week and at 12 months after surgery.

The following muscles were included in the analysis: musculi longissimi (main lumbar component of the erector spinae muscle) and musculi multifidii. The sagittal plane served as a guide for selecting the relevant transaxial slices. The centers of the intervertebral discs' superior and inferior adjacent segments in the sagittal plane were used to define the superior and inferior margins of the regions of interest (ROIs) for segmental muscle evaluation. A separate ROI was defined for each index segment (L3-4 to L5-S1 for index segment L4-5; L4-5 to S1-2 for index segment L5-S1) and its superior adjacent segment (L2-3 to L4-5 for index segment L4-5; L3-4 to L5-S1 for index segment L5-S1). The standard Digital Imaging and Com- munications in Medicine (DICOM) data were recalculated and analyzed with the digital picture-editing software Amira 5.2.0 (Visage Imaging).

Before measurement, a histogram of tissue signal intensity (in Hounsfield units [HU]) was created to define the thresholds for air, bone, and fat and muscle tissue. Slice by slice (transaxial), the paravertebral muscles were semiautomatically selected on both sides of the vertebra. For simplicity, musculi longissimi and musculi multifidii were evaluated together. Changes in Gy values and signal intensity in the images caused by artifact radiation around the implants were excluded from measurements of the 1-week postoperative CT, with a safety margin of $1 \mathrm{~mm}$. This exclusion area and safety margin was copied slice by slice to the 12-month postoperative CT for equal exclusion at both time points. Tissue-specific regions of all slices were summarized for automated calculation of relative fat content $\left(\mathrm{F}_{\text {rel. }}=\mathrm{V}_{\text {fat }} / \mathrm{V}_{\text {overall }}\right.$ in $\left.\%\right)$ and muscle tissue volume $\left(\mathrm{V}_{\text {muscle }}\right.$ in $\left.\mathrm{cm}^{3}\right)$. Initial (1 week) muscle tissue volume $\left(\mathrm{V}_{\text {muscle } 1 \text { week }}\right)$, initial fat content $\left(\mathrm{F}_{\text {rel. } 1 \text { week }}\right)$, residual muscle tissue volume in relation to initial volume $\left(\mathrm{V}_{\text {muscle rel. } 12 \text { months }}\right.$, Fig. 1), as well as changes of the relative fat content $\left(\Delta \mathrm{F}_{\text {rel. }}\right)$, were compared between the groups.

The data from this study were analyzed using the IBM SPSS statistics software version 22.0.0.1 (IBM Corp.) and Prism 5.0 (GraphPad Software Inc.). Intergroup comparisons of postoperative ODI and VAS were conducted with a 2-sided, 2-way analysis of variance for repeated measures (RM-ANOVA). Intragroup testing of ODI and VAS over time was performed with a 2-sided, 1-way RM-ANOVA. Post hoc tests with Bonferroni correction were performed for all ANOVAs. The normality of the distribution was verified using the Kolmogorov-Smirnov test prior to applying parametrical testing. The difference in the radiological parameters between the groups was determined using a 2-sided Mann-Whitney U-test. For intragroup

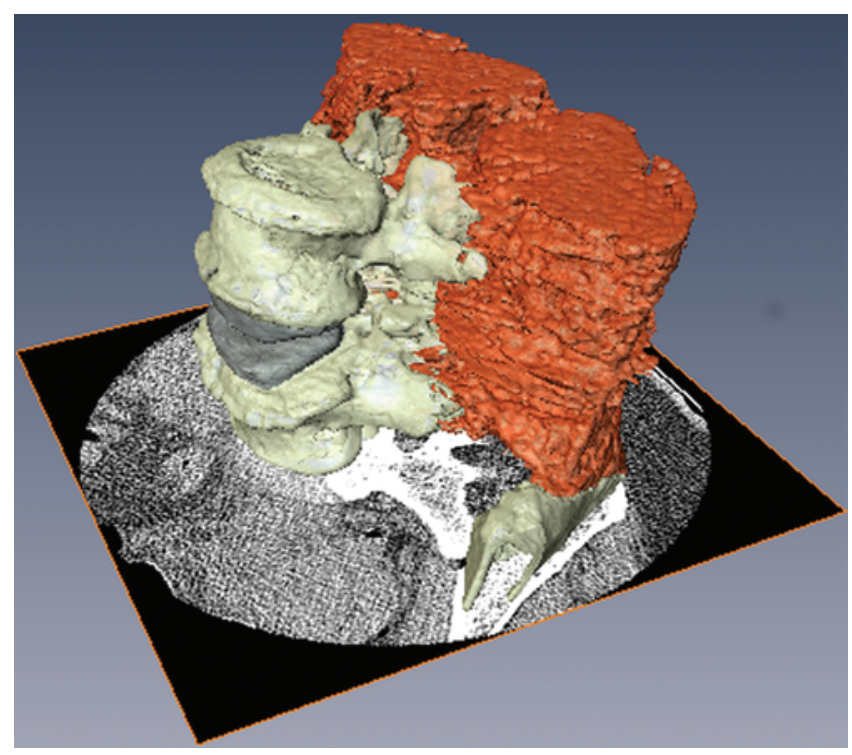

FIG. 1. The image shows a computerized 3D model of the muscle tissue volume (red) at the index segment L4-5 based on CT data at 12-month follow-up. Anteriorly between the vertebral bodies, the TDR (gray) is visible. Figure is available in color online only. 
comparisons of the radiological parameters, a Wilcoxon test was used. Categorical variables were tested with the chi-square test. The significance level for all of the statistical tests was set at $\mathrm{p}<0.05$.

\section{Results}

Two patients in the TDR group were lost during followup and were therefore excluded from the analysis. In 1 patient from the TDR group, intraoperative bleeding caused by injury of the vena iliaca communis was resolved with suturing. In the ALIF group, 1 patient presented with superficial wound dehiscence that was successfully treated with surgical revision and suture.

\section{Clinical Results}

All of the patients demonstrated a significant clinical improvement with regard to back pain (VAS: ANOVA $\left.\mathrm{p}_{\text {time }}<0.001\right)$ and function (ODI: ANOVA $\mathrm{p}_{\text {time }}<0.001$ ), which is presented in Fig. 2 (see also for intragroup post hoc tests). No significant differences between the groups were observed regarding VAS or ODI over time.

\section{Radiological Results}

No implant-related complications occurred in either group over time. The ROM measurements exhibited a significant difference $(\mathrm{p}<0.001)$ between the TDR (median $\mathrm{ROM}=11.4^{\circ}$, interquartile range $\left.[\mathrm{IQR}] 4.95^{\circ}\right)$ and ALIF (median ROM $=0.4^{\circ}$, IQR $1.30^{\circ}$ ) groups. On CT, no implant-associated complications of loosening or migration were observed. CT-based fusion criteria were fulfilled in $68 \%$ of patients in the ALIF group, whereas in 3 of the TDR patients, the radiographic ROM was $<3^{\circ}$.

\section{Quantitative 3D Muscle Analysis Results}

In all of the patients and in both segments (i.e., index and adjacent segments), the absolute muscle tissue volume $\left(\mathrm{V}_{\text {muscle }}\right)$ decreased and relative fat content $\left(\mathrm{F}_{\text {rel }}\right)$ increased significantly (all had a p <0.001) from 1 week to 12 months postsurgery (Table 2). There was no significant difference between the groups regarding the residual muscle tissue volume ( $\left.\mathrm{V}_{\text {muscle rel. 12 months }}, \mathrm{p}=0.149\right)$ and change in the relative fat content $\left(\Delta \mathrm{F}_{\text {rel, }}, \mathrm{p}=0.391\right)$ at the index segment (Fig. $3)$. However, at the adjacent segment, a small but signifi- cant difference between the TDR and ALIF groups was observed according to $\mathrm{V}_{\text {muscle rel. } 12 \text { months }}(\mathrm{p}=0.006)$ and $\Delta \mathrm{F}_{\text {rel }}$ $(\mathrm{p}=0.007)$ (Fig. 4).

\section{Discussion}

Contrary to the hypothesis of the present study, at the index and adjacent segments, we surprisingly found a significant but small decrease in posterior paravertebral muscle tissue volume after single-level motion preservation (TDR) and motion restriction (stand-alone ALIF) treatment 12 months after surgery. This decrease was accompanied by a small but significant increase in relative fat content of these muscles. However, differences between the procedures were only observed at the superior adjacent level, which showed a higher residual muscle tissue volume and lower relative fat content increase in the ALIF group. Nevertheless, the observed changes did not lead to significant clinical superiority during follow-up.

To our knowledge, this is the first analysis comparing the posterior paravertebral muscle changes of a treated and superior adjacent segment after TDR and stand-alone ALIF procedures that excludes direct damage of the posterior surgical approach. In addition, we believe that the $3 \mathrm{D}$ character of the present analysis provides a more accurate portrayal of the structural changes of the muscles compared with the cross-sectional area (CSA) analyses performed in previous studies. ${ }^{1}$ Therefore, we were able to detect small changes and differences between the groups at the adjacent segment.

Nevertheless, the observed changes are less than 3\% and are certainly functionally and clinically irrelevant, at least at 12 months postsurgery. Regarding this observation, it is known from comparisons of healthy volunteers and patients with low-back pain that the difference in multifidus muscle CSA between symptomatic and asymptomatic individuals ranges from $14 \%$ to $36 \% .{ }^{8}$ Moreover, a high correlation of severe fatty muscle infiltration of more than $50 \%$ with prevalence of low-back pain was described. ${ }^{17}$ According to this result, Le Huec et al. found this cutoff to be relevant in the outcome of patients following TDR. ${ }^{18}$

Although we did not perform a direct comparison, the previously described muscle tissue atrophy and fatty degeneration following posteriorly instrumented fusion clearly exceeds the atrophy and degeneration after TDR
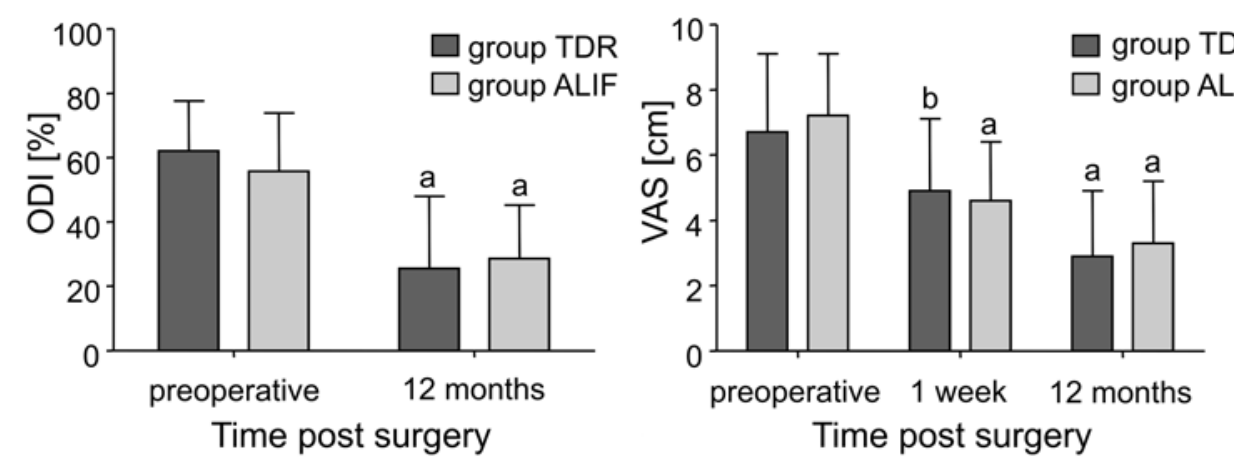

FIG. 2. Results of the clinical scores are shown for function (ODI) (left) and low-back pain (VAS) (right) for the ALIF and TDR groups over the follow-up period. Whiskers indicate a single SD. The lowercase letters $a(p<0.001)$ and $b(p<0.01)$ represent significant improvement in post hoc tests compared with the preoperative status. 
TABLE 2. Muscle tissue volume $\left(\mathrm{V}_{\text {muscle }}\right)$ and relative fat content $\left(\mathrm{F}_{\text {rel }}\right)$ of the index and adjacent segments at 1 week and at 12 months after surgery

\begin{tabular}{|c|c|c|c|c|}
\hline \multirow[b]{2}{*}{ Group } & \multirow[b]{2}{*}{ Segment } & \multirow[b]{2}{*}{ Parameter* } & \multicolumn{2}{|c|}{ Median (IQR) } \\
\hline & & & $1 \mathrm{Wk}$ & 12 Mos \\
\hline \multirow[t]{4}{*}{ TDR } & Index & $\mathrm{V}_{\text {muscle }}$ & 185.8 (38.8) & $183.2(42.6)$ \\
\hline & & $\mathrm{F}_{\mathrm{rel}}$ & $13.6(3.1)$ & $14.9(3.9)$ \\
\hline & Adjacent & $V_{\text {muscle }}$ & $216.5(34.9)$ & $211.3(38.9)$ \\
\hline & & $\mathrm{F}_{\text {rel }}$ & $5.4(2.8)$ & $6.7(2.5)$ \\
\hline \multirow[t]{4}{*}{ ALIF } & Index & $V_{\text {muscle }}$ & $172.9(58.2)$ & $167.4(56.1)$ \\
\hline & & $\mathrm{F}_{\text {rel }}$ & $16.4(9.6)$ & $18.5(9.9)$ \\
\hline & Adjacent & $\mathrm{V}_{\text {muscle }}$ & $198.9(72.1)$ & $197.7(71.8)$ \\
\hline & & $\mathrm{F}_{\text {rel }}$ & $2.9(1.9)$ & $3.4(1.9)$ \\
\hline
\end{tabular}

* Values for $V_{\text {muscle }}$ are expressed in $\mathrm{cm}^{3}$, and values for $F_{\text {rel }}$ are expressed as percentages.

and stand-alone ALIF in the present study, even when using the same evaluation method. ${ }^{67,13,15,24,34}$ Therefore, it can be concluded that fatty degeneration and volume atrophy of the paravertebral muscles is more strongly correlated to direct damage caused by the posterior surgical approach than to iatrogenic changes in function based on motion preservation or restriction. Consequently, motion preservation does not show a clear benefit and motion restriction does not show a clear disadvantage for the posterior lumbar paravertebral muscles in cases with single-level disc degeneration based on an anterior-only approach.

In relation to the literature, only Motosuneya et al. studied the effect of a stand-alone ALIF procedure on the paravertebral muscles and compared it with the effects after a posterior approach-based fusion and decompression procedures using a CSA analysis based on MRI. ${ }^{24}$ Adjacent segments were not studied, and procedure-related clinical outcomes were not reported. Interestingly, Motosuneya et al. observed a mean CSA-based muscle atrophy ratio (residual muscle tissue at follow-up in relation to initial muscle tissue area/volume) of approximately 0.94 at the index segment compared with 0.98 in the volume-based evaluation of the present study after single-level ALIF. These differences could be explained by the different evaluation methods, different postoperative regimens for mobilization, segmental distribution of ALIFs (see Table 1 for the present study; in Motosuneya et al., ${ }^{24}$ L2-3, L3-4, L4-5, and L5-S1 = 2, 1, 7, and 1, respectively), and time between surgery and evaluation (12 months in the present study vs 16 months in the study by Motosuneya et al.). In particular, the mobilization regimen may play an important role because of the effects of muscle arrest on muscle atrophy. ${ }^{4,19}$ In the present study, the patients were not restricted in terms of mobilization and no orthosis was prescribed, whereas the patients in the study by Motosuneya et al. were required to wear a hard orthosis for approximately 3 months. For TDR, to our knowledge, no studies are currently available. Moreover, we tried to minimize a possible confounding effect of postoperative training differences by randomization of patients to the groups and by determination of the physiotherapy goals and duration.

Surprisingly, the only significant radiological differences between the groups were found at the adjacent segment, which showed a higher residual muscle volume in the fusion group. Although there were no clinical differences, we hypothesize that the loss of function at the index segment in the ALIF group resulted in an increased muscle load to the superior adjacent segment compared with the results after TDR. Thus, because of the "training effect," muscle atrophy here was probably less pronounced in the TDR group.

The overall atrophy and fatty degeneration ratio at the adjacent segments after both of the anterior-only treatment options appears to be rather low. This could be a relevant beneficial factor with regard to the development or progression of adjacent-segment degeneration. Regarding TDR, a significantly lower ratio of adjacent-segment degeneration was reported compared with the fusion approach. ${ }^{14}$ This result may be predominantly related to the lack of direct approach-dependent damage to the posterior muscles and not caused by motion preservation. Interestingly, a higher rate of adjacent-segment degeneration was also observed for a transpedicularly stabilized fusion where a posterior surgical approach was used..$^{25}$ Thus, direct muscle damage as well as other factors, such as facet joint destruction by placement of the pedicle screws, $3,23,31$ may play a role in adjacent-segment degeneration.

Based on the results of our study, we did not find TDR to be superior. In addition, to our knowledge, neither the long-term superiority of a motion-preserving stabilization system in comparison with fusion, nor the long-term ben-
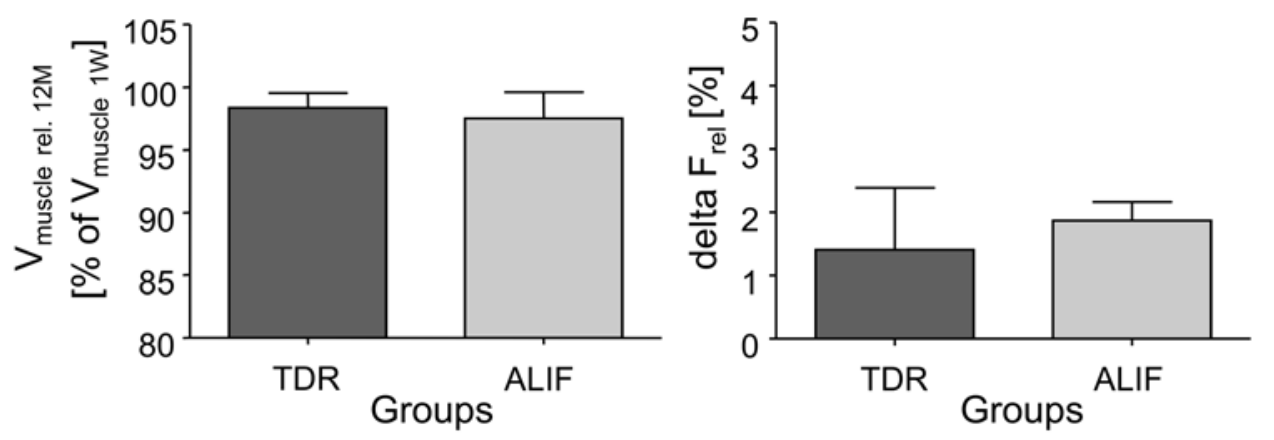

FIG. 3. The residual muscle tissue volume is illustrated at 12 months in relation to that at 1 week after surgery $\left(V_{\text {muscle rel. } 12 \text { months }}\right)$ (left) and relative fat content change between 1 week and 12 months after surgery $\left(\Delta \mathrm{F}_{\text {rel. }}\right.$ ) (right) between the ALIF and TDR groups at the index segment. Whiskers indicate a single SD. 

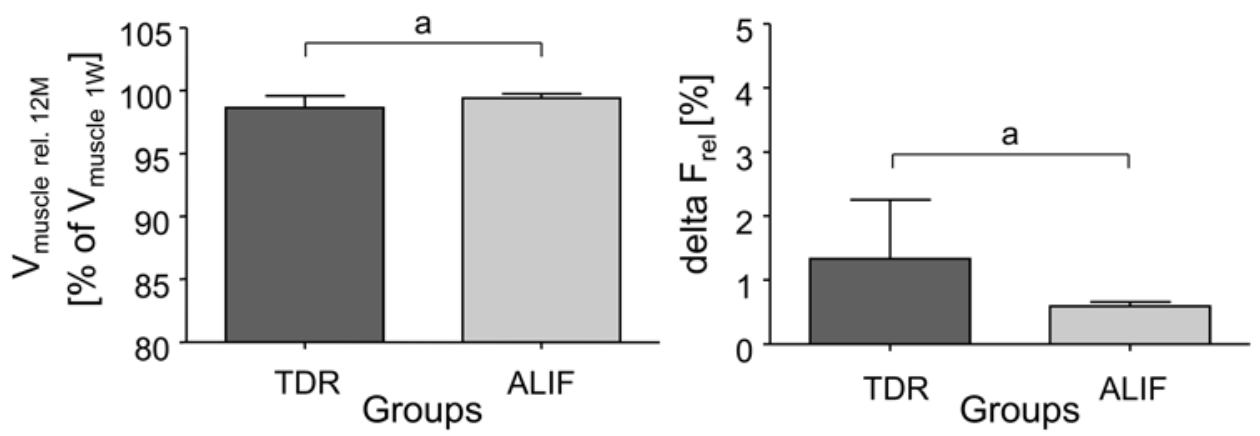

FIG. 4. The residual muscle tissue volume is illustrated at 12 months in relation to that at 1 week after surgery $\left(V_{\text {muscle rel. } 12 \text { months }}\right)$ (left) and relative fat content change between 1 week and 12 months after surgery $\left(\Delta \mathrm{F}_{\text {rel. }}\right)$ (right) between the ALIF and TDR groups at the superior adjacent segment. Whiskers indicate a single SD. The lowercase letter a represents significance in the group comparisons $(p<0.01)$.

efit of muscle-sparing surgical approaches to the lumbar spine, have been clinically demonstrated. Therefore, the controversy over the benefits of motion-preserving techniques and implants and the superiority of muscle-sparing approaches could not be resolved.

The present study is not without limitations. First, the follow-up is relatively short. Nevertheless, we believe that the muscle adaptation process mostly occurs during the first few months after a surgical intervention. However, even the small muscular changes observed after 12 months could possibly lead to significant clinical effects over a long-term follow-up.

Second, the different segmental and sex distributions between the groups could lead to a difference with regard to muscle volume and fat content. Similar effects result from differences in body height (e.g., larger body height $=$ larger evaluation volume). However, based on a comparison of the relative and intraindividual changes, we have attempted to minimize these errors. In addition, we have performed volume evaluation because in comparison with 2D analyses, it strongly correlates with mental and physical outcomes and pain. ${ }^{35}$ It also increases the precision of predicting muscular function, which has been shown in extremity muscle studies. ${ }^{11}$

Third, to our knowledge, despite their frequent use and similarly and acceptably rated reliabilities, ${ }^{16}$ the sensitivities and specificities of CT- or MRI-based muscle degeneration analyses have not yet been reported, which raises the possibility of a systematic error. Finally, despite randomization and differences in patients' exercise programs, compliance, and activity levels, postoperative pain and function were potential confounders that could not be completely excluded.

\section{Conclusions}

Despite the different concepts of motion restriction and preservation, we demonstrated that both single-level ALIF and TDR lead to only small and similar changes of the posterior paravertebral muscles in terms of volume atrophy and fatty degeneration at the index and superior adjacent segments at 12 months postsurgery. Therefore, although the clinical outcomes were not affected by the observed muscular changes, we conclude that the expected negative influence of motion restriction on the posterior muscles does not occur on a clinically relevant level compared with the influence of motion preservation.

\section{Acknowledgments}

This study was financially supported in part by the German Research Foundation (DFG) under project no. PU 510/2-1. The funders had no role in the study design, data collection and analysis, decision to publish, or preparation of the manuscript.

\section{References}

1. Akagi R, Takai Y, Ohta M, Kanehisa H, Kawakami Y, Fukunaga T: Muscle volume compared to cross-sectional area is more appropriate for evaluating muscle strength in young and elderly individuals. Age Ageing 38:564-569, 2009

2. Borenstein D: Epidemiology, etiology, diagnostic evaluation, and treatment of low back pain. Curr Opin Rheumatol 8:124-129, 1996

3. Chen Z, Zhao J, Xu H, Liu A, Yuan J, Wang C: Technical factors related to the incidence of adjacent superior segment facet joint violation after transpedicular instrumentation in the lumbar spine. Eur Spine J 17:1476-1480, 2008

4. Danielsson AJ, Romberg K, Nachemson AL: Spinal range of motion, muscle endurance, and back pain and function at least 20 years after fusion or brace treatment for adolescent idiopathic scoliosis: a case-control study. Spine (Phila Pa 1976) 31:275-283, 2006

5. Fairbank JC, Couper J, Davies JB, O'Brien JP: The Oswestry low back pain disability questionnaire. Physiotherapy 66:271-273, 1980

6. Fan SW, Hu ZJ, Fang XQ, Zhao FD, Huang Y, Yu HJ: Comparison of paraspinal muscle injury in one-level lumbar posterior inter-body fusion: modified minimally invasive and traditional open approaches. Orthop Surg 2:194-200, 2010

7. Fan SW, Hu ZJ, Zhao FD, Zhao X, Huang Y, Fang X: Multifidus muscle changes and clinical effects of one-level posterior lumbar interbody fusion: minimally invasive procedure versus conventional open approach. Eur Spine J 19:316-324, 2010

8. Fortin M, Macedo LG: Multifidus and paraspinal muscle group cross-sectional areas of patients with low back pain and control patients: a systematic review with a focus on blinding. Phys Ther 93:873-888, 2013

9. Freynhagen R, Baron R: The evaluation of neuropathic components in low back pain. Curr Pain Headache Rep 13:185-190, 2009

10. Fujiwara A, Tamai K, Yamato M, An HS, Yoshida H, Saotome $\mathrm{K}$, et al: The relationship between facet joint osteoarthritis and disc degeneration of the lumbar spine: an MRI study. Eur Spine J 8:396-401, 1999 
11. Fukunaga T, Miyatani M, Tachi M, Kouzaki M, Kawakami $\mathrm{Y}$, Kanehisa $\mathrm{H}$ : Muscle volume is a major determinant of joint torque in humans. Acta Physiol Scand 172:249-255, 2001

12. Gerbershagen HU, Lindena G, Korb J, Kramer S: [Healthrelated quality of life in patients with chronic pain.] Schmerz 16:271-284, 2002 (Ger)

13. Gille O, Jolivet E, Dousset V, Degrise C, Obeid I, Vital JM, et al: Erector spinae muscle changes on magnetic resonance imaging following lumbar surgery through a posterior approach. Spine (Phila Pa 1976) 32:1236-1241, 2007

14. Harrop JS, Youssef JA, Maltenfort M, Vorwald P, Jabbour P, Bono CM, et al: Lumbar adjacent segment degeneration and disease after arthrodesis and total disc arthroplasty. Spine (Phila Pa 1976) 33:1701-1707, 2008

15. Hartwig T, Streitparth F, Gross C, Müller M, Perka C, Putzier M, et al: Digital 3-dimensional analysis of the paravertebral lumbar muscles after circumferential single-level fusion. J Spinal Disord Tech 24:451-454, 2011

16. Hu ZJ, He J, Zhao FD, Fang XQ, Zhou LN, Fan SW: An assessment of the intra- and inter-reliability of the lumbar paraspinal muscle parameters using CT scan and magnetic resonance imaging. Spine (Phila Pa 1976) 36:E868-E874, 2011

17. Kjaer P, Bendix T, Sorensen JS, Korsholm L, Leboeuf-Yde C: Are MRI-defined fat infiltrations in the multifidus muscles associated with low back pain? BMC Med 5:2, 2007

18. Le Huec JC, Basso Y, Aunoble S, Friesem T, Bruno MB: Influence of facet and posterior muscle degeneration on clinical results of lumbar total disc replacement: two-year follow-up. J Spinal Disord Tech 18:219-223, 2005

19. LeBlanc AD, Schneider VS, Evans HJ, Pientok C, Rowe R, Spector E: Regional changes in muscle mass following 17 weeks of bed rest. J Appl Physiol (1985) 73:2172-2178, 1992

20. Mayer TG, Vanharanta H, Gatchel RJ, Mooney V, Barnes D, Judge L, et al: Comparison of CT scan muscle measurements and isokinetic trunk strength in postoperative patients. Spine (Phila Pa 1976) 14:33-36, 1989

21. Meyerding HW: Spondylolisthesis; surgical fusion of lumbosacral portion of spinal column and interarticular facets; use of autogenous bone grafts for relief of disabling backache. J Int Coll Surg 26:566-591, 1956

22. Modic MT, Steinberg PM, Ross JS, Masaryk TJ, Carter JR: Degenerative disk disease: assessment of changes in vertebral body marrow with MR imaging. Radiology 166:193199, 1988

23. Moshirfar A, Jenis LG, Spector LR, Burke PJ, Losina E, Katz JN, et al: Computed tomography evaluation of superiorsegment facet-joint violation after pedicle instrumentation of the lumbar spine with a midline surgical approach. Spine (Phila Pa 1976) 31:2624-2629, 2006

24. Motosuneya T, Asazuma T, Tsuji T, Watanabe H, Nakayama $\mathrm{Y}$, Nemoto K: Postoperative change of the cross-sectional area of back musculature after 5 surgical procedures as assessed by magnetic resonance imaging. J Spinal Disord Tech 19:318-322, 2006

25. Park P, Garton HJ, Gala VC, Hoff JT, McGillicuddy JE: Adjacent segment disease after lumbar or lumbosacral fusion: review of the literature. Spine (Phila Pa 1976) 29:19381944, 2004

26. Pfirrmann CW, Resnick D: Schmorl nodes of the thoracic and lumbar spine: radiographic-pathologic study of prevalence, characterization, and correlation with degenerative changes of 1,650 spinal levels in 100 cadavers. Radiology 219:368-374, 2001

27. Putzier M, Streitparth F, Hartwig T, Perka CF, Hoff EK, Strube P: Can discoblock replace discography for identifying painful degenerated discs? Eur J Radiol 82:1463-1470, 2013

28. Putzier M, Strube P, Funk JF, Gross C, Mönig HJ, Perka C, et al: Allogenic versus autologous cancellous bone in lumbar segmental spondylodesis: a randomized prospective study. Eur Spine J 18:687-695, 2009

29. Rohlmann A, Lauterborn S, Dreischarf M, Schmidt H, Putzier M, Strube P, et al: Parameters influencing the outcome after total disc replacement at the lumbosacral junction. Part 1: misalignment of the vertebrae adjacent to a total disc replacement affects the facet joint and facet capsule forces in a probabilistic finite element analysis. Eur Spine J 22:22712278, 2013

30. Sachs BL, Vanharanta H, Spivey MA, Guyer RD, Videman $\mathrm{T}$, Rashbaum RF, et al: Dallas discogram description. A new classification of CT/discography in low-back disorders. Spine (Phila Pa 1976) 12:287-294, 1987

31. Shah RR, Mohammed S, Saifuddin A, Taylor BA: Radiologic evaluation of adjacent superior segment facet joint violation following transpedicular instrumentation of the lumbar spine. Spine (Phila Pa 1976) 28:272-275, 2003

32. Strube P, Hoff E, Hartwig T, Perka CF, Gross C, Putzier M: Stand-alone anterior versus anteroposterior lumbar interbody single-level fusion after a mean follow-up of 41 months. J Spinal Disord Tech 25:362-369, 2012

33. Strube P, Hoff EK, Schürings M, Schmidt H, Dreischarf M, Rohlmann A, et al: Parameters influencing the outcome after total disc replacement at the lumbosacral junction. Part 2: distraction and posterior translation lead to clinical failure after a mean follow-up of 5 years. Eur Spine J 22:22792287, 2013 (Erratum in Eur Spine J 23:2758, 2014)

34. Suwa H, Hanakita J, Ohshita N, Gotoh K, Matsuoka N, Morizane A: Postoperative changes in paraspinal muscle thickness after various lumbar back surgery procedures. Neurol Med Chir (Tokyo) 40:151-155, 2000

35. Waschke A, Hartmann C, Walter J, Dünisch P, Wahnschaff F, Kalff R, et al: Denervation and atrophy of paraspinal muscles after open lumbar interbody fusion is associated with clinical outcome-electromyographic and CT-volumetric investigation of 30 patients. Acta Neurochir (Wien) 156:235-244, 2014

\section{Disclosure}

The authors report no conflict of interest concerning the materials or methods used in this study or the findings specified in this paper.

\section{Author Contributions}

Conception and design: Strube, Putzier, Hartwig. Acquisition of data: Streitparth, Hoff, Hartwig. Analysis and interpretation of data: all authors. Drafting the article: Strube, Hartwig. Critically revising the article: Putzier, Streitparth, Hoff. Reviewed submitted version of manuscript: Putzier, Hoff, Hartwig. Approved the final version of the manuscript on behalf of all authors: Strube. Statistical analysis: Strube. Administrative/technical/material support: Putzier, Streitparth. Study supervision: Putzier.

\section{Supplemental Information}

\section{Previous Presentation}

Portions of this work were presented in abstract form at the 6th German Spine Society Congress, Hamburg, Germany, December 10, 2011.

\section{Correspondence}

Patrick Strube, Klinik für Orthopädie der Friedrich-SchillerUniversität Jena, Waldkrankenhaus "Rudolf Elle" gGmbH, Klosterlausnitzer Str. 81, 07607 Eisenberg, Germany. email: p.strube@krankenhaus-eisenberg.de. 